\title{
Wound outcome in combat injuries is associated with a unique set of protein biomarkers
}

\author{
Brett A Chromy ${ }^{1 *}$, Angela Eldridge ${ }^{1,2}$, Jonathan A Forsberg ${ }^{3,4,8}$, Trevor S Brown ${ }^{4}$, Benjamin C Kirkup ${ }^{6,7}$, \\ Crystal Jaing ${ }^{7}$, Nicholas A Be ${ }^{7}$, Eric Elster ${ }^{5,8}$ and Paul A Luciw ${ }^{1,2}$
}

\begin{abstract}
Background: The ability to forecast whether a wound will heal after closure without further debridement(s), would provide substantial benefits to patients with severe extremity trauma.

Methods: Wound effluent is a readily available material which can be collected without disturbing healthy tissue. For analysis of potential host response biomarkers, forty four serial combat wound effluent samples from 19 patients with either healing or failing traumatic- and other combat-related wounds were examined by 2-D DIGE. Spot map patterns were correlated to eventual wound outcome (healed or wound failure) and analyzed using DeCyder 7.0 and differential proteins identified via LC-MS/MS.

Results: This approach identified 52 protein spots that were differentially expressed and thus represent candidate biomarkers for this clinical application. Many of these proteins are intimately involved in inflammatory and immune responses. Furthermore, discriminate analysis further refined the 52 differential protein spots to a smaller subset of which successfully differentiate between wounds that will heal and those that will fail and require further surgical intervention with greater than $83 \%$ accuracy.

Conclusion: These results suggest candidates for a panel of protein biomarkers that may aid traumatic wound care prognosis and treatment. We recommend that this strategy be refined, and then externally validated, in future studies of traumatic wounds.
\end{abstract}

Keywords: Traumatic wound, Proteomics, 2-D DIGE, Wound effluent, Biomarker discovery, Wound dehiscence

\section{Introduction}

The combination of effective body armor and the use of improvised explosion devices in modern warfare have greatly increased the incidence of severe survivable traumatic injuries [1-4]. Comprising approximately half of all current combat wounds, this mechanism of injury predominately affects the extremities and devastates skin, musculoskeletal tissue, the neurovascular system, and bone [4-7]. Several factors can contribute to the ability of a wound to heal or to dehisce, including the extent of injury, time from wound occurrence to care, individual immune and inflammatory responses, and microbial colonization. However, no widely used prognostic assay quantitatively predicts whether a traumatic wound will heal normally or dehisce after surgical closure.

\footnotetext{
* Correspondence: brett.chromy@ucdmc.ucdavis.edu

${ }^{1}$ Department of Pathology and Laboratory Medicine, School of Medicine, University of California at Davis, Davis, CA, USA

Full list of author information is available at the end of the article
}

Failure of the healing process of chronic wounds incurs massive health care costs, totaling up to $\$ 3$ billion per year [8]. In general, the healing of wounds is a tightly regulated process involving hemostasis, inflammation, cell proliferation, and tissue remodeling. Wounds with impaired healing do not progress through these normal stages due to many factors including local wound characteristics, such as, oxygenation, microbial presence, and venous supply [9]. The inflammation phase is critical for the removal of contaminating organisms and, if removal is not sufficient, the remaining bacteria and endotoxins can lead to a prolonged inflammatory response [10]. One of the most commonly cited wound outcome indicators is the extent of microbial presence [5], which is clinically binned into one of three categories: contamination (non-replicating organisms present), colonization (replicating organisms present) and local infection/critical colonization (intermediate stage with local tissue 
response) [10]. Although microbial presence is associated with wound outcome, current clinical microbiology is not sufficient to predict non-healing, therefore, alternative methods need to be explored.

Current research on wound outcome focuses on correlating changes in levels of certain host proteins, including chemokines, cytokines, metalloproteinases and other proteases, and inflammatory marker proteins; these studies indicate that poor combat wound healing is associated with dysregulation of the inflammatory response [5,11-13]. In this report, we expand upon previous effort by describing a comprehensive study that aims to analyze the wound effluent proteome and provide a preliminary biomarker panel of proteins that can differentiate between uneventful healing and wound failure (such as dehiscence, failure of graft or flap, removal of biologic matrix) after surgical closure. If successful, these discriminating proteins can be further developed for use as a prognostic tool to aid physicians in predicting wound outcome and thus providing optimal care for traumatic- and otherwise combat-related injuries.

\section{Materials and methods}

\section{Patients and sample collection}

The study methodology is as reported elsewhere [5,11] and is reiterated here for completeness. In brief, serial samples were collected in an observational study with prospective data collection in accordance with the institutional review board of the Walter Reed National Military Medical Center (Bethesda, MD). All service members evacuated to the National Capital Area from Iraq and Afghanistan that had sustained high-energy penetrating injuries to one or more extremities and were without confounding co-morbid conditions, such as immune disorders, connective tissue disorders, or any conditions requiring immunosuppressive agents, were eligible for inclusion. Surgical debridement, lavage, and negative-pressure wound therapy (NPWT) were repeated every 48-72 hours until surgical wound closure or coverage at the discretion of the attending surgeon and in accordance with current institutional standards of practice. Patients were followed throughout their recovery for a minimum of six weeks to determine whether their wounds healed normally or dehisced (Table 1).

Wound effluent samples $(\geq 30 \mathrm{ml})$ were collected from the NPWT canister (without gel pack; Kinetic Concepts, Inc., San Antonio, TX) over a 12-hour period prior to each wound debridement and 2 hours following the first surgical debridement and subsequent surgical debridements. The samples used in this study were collected from up to three wounds for up to three serial debridements. Samples were treated like serum and centrifuged at $2500 \mathrm{x} \mathrm{g}$ for 10 minutes to remove particulate matter and emboli. Effluent supernatants were transferred to
Table 1 Patient demographics and clinical characteristics

\begin{tabular}{|c|c|c|}
\hline Patient Demographics and Clinical Characteristics & $\begin{array}{l}\text { Healed } \\
n=21\end{array}$ & $\begin{array}{c}\text { Dehisced } \\
n=23\end{array}$ \\
\hline Age, y & $23.7 \pm 3.8$ & $22 \pm 3.2$ \\
\hline BMI, mean (SD) & $26 \pm 2.4$ & $25 \pm 3.8$ \\
\hline \multicolumn{3}{|l|}{ Gender, $n(\%)$} \\
\hline Male & $21(100 \%)$ & $23(100 \%)$ \\
\hline Female & $0(0 \%)$ & $0(0 \%)$ \\
\hline \multicolumn{3}{|l|}{ Wound Location, $n$} \\
\hline Upper Body & 19 & 0 \\
\hline Lower Body & 2 & 23 \\
\hline \multicolumn{3}{|l|}{ Wound Type, $n$} \\
\hline Soft Tissue Infection & 12 & 17 \\
\hline Fasciotomy & 5 & 7 \\
\hline Amputation & 3 & 0 \\
\hline Open Fracture & 1 & 0 \\
\hline \multicolumn{3}{|l|}{ Type of Closure, $n$} \\
\hline Primary & 13 & 9 \\
\hline Integra & 2 & 12 \\
\hline Graft & 4 & 1 \\
\hline Flap & 2 & 1 \\
\hline Injury Severity Score, mean (SD) & $20 \pm 8.3$ & $17 \pm 7.3$ \\
\hline No. of Total Surgeries, mean (SD) & $3.8 \pm 1.2$ & $3.6 \pm 1.4$ \\
\hline \multicolumn{3}{|l|}{ Presence of Traumatic Brain Injury, $n$} \\
\hline Yes & 16 & 7 \\
\hline No & 2 & 13 \\
\hline Unknown & 3 & 3 \\
\hline \multicolumn{3}{|l|}{ Presence of Heterotrophic Ossification, $n$} \\
\hline Yes & 16 & 21 \\
\hline No & 5 & 2 \\
\hline Days from Injury to Arrival at Facility, mean (SD) & $4.2 \pm 1.6$ & $4.4 \pm 1.4$ \\
\hline Days from Injury to Wound Closure, mean (SD) & $12.1 \pm 3.8$ & $11.7 \pm 4.9$ \\
\hline Days from Injury to Sample Collection, mean (SD) & $6.2 \pm 1.4$ & $6.6 \pm 1.5$ \\
\hline Days from Sample Collection to Closure, mean (SD) & $5.9 \pm 3.8$ & $5.0 \pm 4.5$ \\
\hline
\end{tabular}

The demographic and clinical characteristics of the 20 patients that comprised the 44 wound effluent samples are displayed.

individually labeled polypropylene tubes, flash-frozen in liquid nitrogen, and stored at $-80^{\circ} \mathrm{C}$ until analysis.

\section{Removal of highly abundant proteins}

Depletion of high abundant proteins was performed according to manufacturer's instructions. Briefly, patient wound effluent was diluted five fold in Buffer A (Agilent Technologies) into $200 \mu \mathrm{l}$ total volume and centrifuged through a 0.22 micron spin filter (Millipore) tube at $16,000 \mathrm{xg}$ for $5 \mathrm{~min}$ to remove particulates. Then effluent fluids were processed using Multiple Affinity Removal Column Human-6 (Agilent Technologies), which specifically removes albumin, IgA, IgG, antitrypsin, transferrin and haptoglobin. A low abundant protein fraction was collected for each sample. Fractions were 
concentrated by precipitation using an equal volume of $20 \%$ trichloroacetic acid solution and incubated at $4^{\circ} \mathrm{C}$ for $30 \mathrm{~min}$. The precipitate was washed twice with cold $100 \%$ acetone, allowed to air dry, and then resuspended in DIGE labeling buffer (7 M urea, $2 \mathrm{M}$ thiourea, $4 \%$ CHAPS, $30 \mathrm{mM}$ Tris, $\mathrm{pH}$ 8.5). Protein quantification was performed using Precision Red Advanced Protein Assay Reagent (Cytoskeleton Inc.).

\section{2-D DIGE analysis}

Crude and high abundant protein depleted effluent samples were separated in 2 dimensions according to GE Life Sciences Ettan DIGE system protocol. Briefly, each sample $(50 \mu \mathrm{g})$ was minimally labeled with $200 \mathrm{pmol}$ $\mathrm{Cy} 3$ or $\mathrm{Cy} 5$ for $30 \mathrm{~min}$, a pooled standard of all $44 \mathrm{ex}$ perimental samples were labeled similarly with Cy2. All labeling reactions were stopped by the addition of $1 \mu \mathrm{l}$ of $1 \mathrm{mM}$ lysine. Individually labeled samples were pooled and added to rehydration buffer (7 M urea, $2 \mathrm{M}$ thiourea, $4 \%$ CHAPS, $1.2 \%$ destreak, $1 \%$ pharmalytes). A final volume of $450 \mu \mathrm{l}$ sample was loaded onto $24 \mathrm{~cm}$ pH3-10NL Immobiline DryStrips (GE Life Sciences) and focused by active overnight rehydration, followed by active isoelectric focusing for a total of 62,500 Vhrs. Strips were equilibrated in SDS equilibration buffer (6 M urea, 30\% glycerol, 2\% SDS) for $15 \mathrm{~min}$ with $10 \mathrm{mg} / \mathrm{ml} \mathrm{DTT}$, then $15 \mathrm{~min}$ in fresh buffer with $25 \mathrm{mg} / \mathrm{ml} 15 \mathrm{~min}$ with iodoacetamide, then applied to DIGE gels (GE Life Sciences) for 2nd dimension separation. The resulting CyDye labeled protein gels were scanned using 100 micron resolution on Typhoon 9410 (GE Life Sciences).

\section{DeCyder multivariate analysis}

Data analysis was carried out using the various modules of DeCyder 2-D 7.0 software (GE Life Sciences). The difference in-gel analysis (DIA) module was used to determine the optimal and average spot detection settings. All 22 gel images were given to the batch processor module with the designated settings to generate spot maps using 2,500 as the estimated number of spots. Cy2 labeled pooled standard was used to normalize spot intensity within each gel. The spot map with the greatest number of detected spots was set as the master gel, and biological variation analysis (BVA) module was then used for automated spot matching across all the gels. Gel matching quality was manually verified, and landmarks were added where improved matching quality was needed. The extended data analysis (EDA) software package (GE Life Sciences) was used for differential protein determination, PCA, hierarchical clustering, k-means partitioning analysis and discriminate analysis calculations [14].

For identification of differential proteins, each sample spot map was assembled into the appropriate experimental group (healed or dehisced wounds), and the average ratio fold-change were calculated. A base set was established using only spots that were matched on greater than $60 \%$ of the spot maps. Spots having fold change $>1.2$ and p-value $<0.05$ (according to [15]) were considered differentially expressed, each spot was manually verified for an acceptable three dimensional characteristic protein profile and for adequate material for subsequent mass spectrometry identification. Spots not meeting these criteria were excluded from further analysis. The set of confirmed differential proteins for each of the experimental group comparisons was used for PCA, hierarchical clustering (heat map and $\mathrm{k}$-means calculations) and discriminate analysis.

\section{Protein digestion and identification}

Differential proteins were excised from a preparative gel with additional protein for identification purposes. Excised gel pieces were destained in $100 \mathrm{mM}$ ammonium bicarbonate for $1 \mathrm{~h}$ at room temperature, dehydrated with successive $100 \%$ acetonitrile washes and dried in a SpeedVac for $30 \mathrm{~min}$. The gel pieces were then rehydrated with $130 \mathrm{ng}$ modified porcine trypsin (Promega) in $50 \mathrm{mM}$ ammonium bicarbonate and incubated for $16 \mathrm{~h}$ at $37^{\circ} \mathrm{C}$. Supernatants were collected and peptides further extracted with 5\% trifluoroacetic acid in 50\% acetonitrile, supernatants and extraction fluid were pooled together. Tryptic peptides were concentrated down to $5 \mu \mathrm{l}$ by SpeedVac and analyzed by a LC-MS/MS LTQ-Orbitrap using nanoflow HPLC with a HALO C18 reversed phase separation column (Bruker-Michrom). The resulting peak lists were searched against the $\mathrm{Hu}-$ man International Protein Index database using the MASCOT search engine according to the following parameters: up to two missed cleavages, peptide mass tolerance of $1.2 \mathrm{Da}$, fragment mass tolerance of $0.6 \mathrm{Da}$, fixed modification carbamidation, and variable modification oxidation $(\mathrm{M})$. Protein identifications with probability score of $95 \%$ or higher and contain at least two unique peptides were considered valid.

\section{Functional classification}

A list of UniProt IDs for the 45 identified differential spots among healed versus dehisced wounds were submitted to the GORetriever online tool to retrieve their $\mathrm{GO}$ annotations. Corresponding GO annotations and online plugin tool CateGOrizer were used to categorize the proteins according to Immune System Gene class classification list, producing a pie chart to display the distribution of involved functions.

\section{Results}

In this study, we characterized the proteome of traumatic wound patient effluent samples $(n=44)$. Effluent was collected at the Naval Medical Research Center 
using NPWT, which uses a vacuum system to enable earlier wound closure.

All effluent samples were subjected to removal of high abundant proteins to improve overall spot clarity and separated by 2-D DIGE according to protocols established by Chromy et al. [16]. Spot maps were analyzed by DeCyder 7.0 by which a total of 1800 spots were detected and quantified in each the 22 gels using the DIA module, and gel-to-gel spot matching was performed using the BVA module. This approach yielded a significant increase in the number of discernible protein spots when compared to a similar analysis of crude wound effluent, which lead to increased sensitivity and opportunity to find novel protein biomarkers.

\section{Differential protein spot determination}

Differential protein spots were matched on greater than $60 \%$ of the spot maps, had a fold change $>1.2$ [15] with a p-value $<0.05$. A total of 52 unique protein spots were determined to be differential; their distribution on the preparative pick gel is shown in Figure 1 . The 52 differential spots were excised and 45 spots were confidently identified yielding 25 unique proteins. Assigned spot number, IPI database number, gene/protein name, MASCOT score, fold change/t-test along with theoretical molecular weight and $\mathrm{pI}$ are displayed for each identified protein in Table 2. Many areas on the gel show several spots in a horizontal line and were determined to be the same protein with slight variations in their pI [17]. Because only some of the spots in the line were determined to be differential, these data indicate that posttranslational modifications of specific proteins are important in discriminating between healed and dehisced effluent samples.

\section{PCA and hierarchical clustering}

The 52 verified differential proteins were used for PCA of the wound effluent sample spot maps. Figure $2 \mathrm{~A}$ shows good separation between healed and dehisced samples, supporting the theory that the host proteome

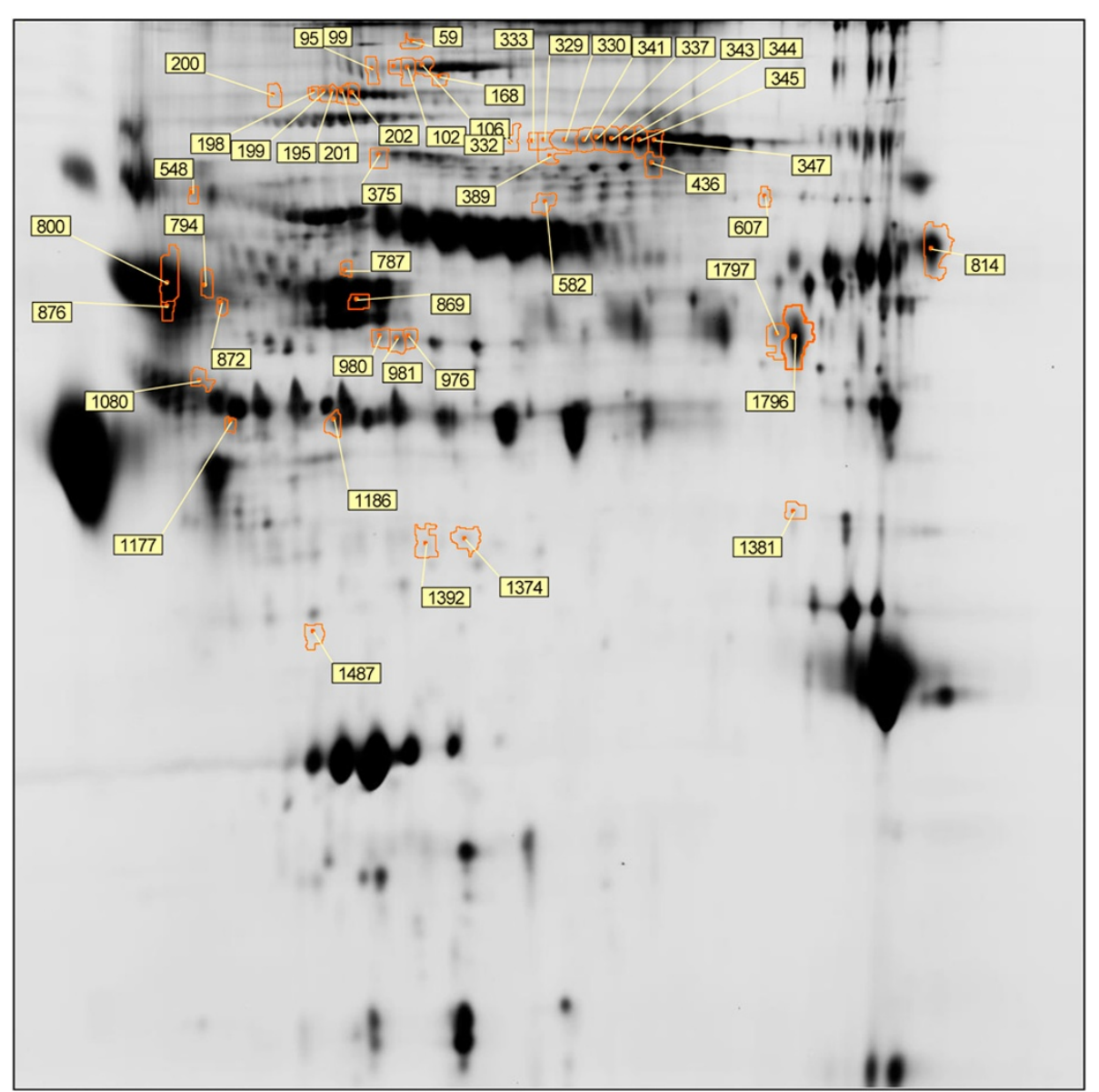

Figure 1 Differential expression analysis. A total of 52 unique protein spots with greater than 1.2 fold change and $p$-value $<0.05$. Each spot boundary is defined in orange and labeled with assigned spot number. Differential spots were excised from the gel and identified via mass spectrometry. 
Table 2 Proteins showing differential responses

\begin{tabular}{|c|c|c|c|c|c|c|c|c|}
\hline Spot No. & IPI No. & $\begin{array}{l}\text { Gene } \\
\text { Name }\end{array}$ & Protein Name & $\begin{array}{l}\text { Mascot } \\
\text { Score } \\
\end{array}$ & $\begin{array}{l}\text { Fold Change } \\
\text { (Healed/ Dehisced) }\end{array}$ & T-test & Th. MW & Th. pl \\
\hline 59 & IPI00440484 & PER1 & Period Circadian protein homolog 1 & 133 & -1.23 & 0.0414 & 137667 & 5.73 \\
\hline $95^{*}$ & IPI00645206 & PCDH17 & Isoform 1 of Protocadherin 17 & 131 & -1.22 & 0.0121 & 127405 & 5.03 \\
\hline $99^{*}$ & IPI00235407 & STK36 & Isoform 1 of Serine/threonine protein kinase 3 & 142 & -1.24 & 0.0018 & 145728 & 5.57 \\
\hline 102 & IPI00185661 & USP32 & Ubiquitin carboxyl terminal hydrolase 32 & 125 & -1.2 & 0.0164 & 145671 & 6.18 \\
\hline 106 & IPI00470744 & PARG & Isoform 2 of Poly (ADP-ribose) glycohydrolase & 113 & -1.22 & 0.0106 & 103503 & 5.58 \\
\hline $168^{*}$ & IPI00290328 & PTPRJ & Receptor type tyrosine protein phosphotase precursor & 130 & -1.51 & 0.0061 & 152960 & 5.8 \\
\hline $195^{*}$ & IPI00017601 & $C P$ & Ceruloplasmin & 101 & -1.27 & 0.0116 & 122983 & 5.44 \\
\hline $198^{*}$ & IPI00017601 & $\mathrm{CP}$ & Ceruloplasmin & 121 & -1.39 & 0.0076 & 122983 & 5.44 \\
\hline 199 & IPI00017601 & $\mathrm{CP}$ & Ceruloplasmin & 182 & -1.31 & 0.0095 & 122983 & 5.44 \\
\hline 200 & IPI00017601 & $C P$ & Ceruloplasmin & 116 & -1.33 & 0.0075 & 122983 & 5.44 \\
\hline 201 & IPI00017601 & $C P$ & Ceruloplasmin & 112 & -1.3 & 0.0254 & 122983 & 5.44 \\
\hline 202 & IPI00017601 & $C P$ & Ceruloplasmin & 154 & -1.31 & 0.0130 & 122983 & 5.44 \\
\hline 329 & IPI00011736 & PIK3R2 & Phosphatidylinositol 3 kinase regulatory subunit 2 & 88 & 1.26 & 0.0259 & 81837 & 6.03 \\
\hline 330 & IPI00783987 & C3 & Complement C3 & 115 & 1.55 & 0.0003 & 188569 & 6.02 \\
\hline 333 & IPI00011736 & PIK3R2 & Phosphatidylinositol 3 kinase regulatory subunit 2 & 111 & 1.25 & 0.0046 & 81837 & 6.03 \\
\hline 337 & IPI00783987 & $\mathrm{C} 3$ & Complement C3 & 88 & 1.53 & 0.0104 & 188569 & 6.02 \\
\hline $341^{*}$ & IPI00783987 & C3 & Complement C3 & 147 & 1.56 & 0.0006 & 188569 & 6.02 \\
\hline $343^{*}$ & IPI00783987 & C3 & Complement C3 & 189 & 1.62 & 0.0006 & 188569 & 6.02 \\
\hline 344 & IPI00783987 & C3 & Complement C3 & 120 & 1.69 & 0.0048 & 188569 & 6.02 \\
\hline 345 & IPI00783987 & C3 & Complement C3 & 79 & 1.59 & 0.0125 & 188569 & 6.02 \\
\hline 347 & IPI00783987 & C3 & Complement C3 & 104 & 1.52 & 0.0339 & 188569 & 6.02 \\
\hline $375^{*}$ & IPI00607814 & XPNPEP1 & Xaa-Pro aminopeptidase 1 Isoform 2 & 121 & 1.23 & 0.0415 & 72746 & 5.67 \\
\hline 389 & IPI00157535 & EPS8L1 & Isoform 4 of Epigrowth factor receptor kinase subunit 8 & 118 & 1.23 & 0.0168 & 88920 & 6.49 \\
\hline 436 & IPI00009089 & FRS3 & Fibroblast growth factor receptor substrate 3 & 121 & -1.28 & 0.0198 & 55169 & 6.81 \\
\hline 582 & IPI00301255 & IGSF21 & Immunoglobulin superfamily member 21 & 109 & -1.23 & 0.0480 & 51855 & 6.48 \\
\hline 602 & IPI00329555 & F7 & Isoform A of Coagulation factor VII & 178 & -1.54 & 0.0232 & 53043 & 6.91 \\
\hline 607 & IPI00329555 & F7 & Isoform A of Coagulation factor VII & 130 & -1.37 & 0.0462 & 53043 & 6.91 \\
\hline 787 & IPI00021891 & FGG & Fibrinogen gamma chain 1 & 135 & 1.33 & 0.0267 & 51511 & 5.37 \\
\hline 794 & IPI00847635 & SERPINA3 & Isoform 1 of alpha-1-antichymotrypsin & 146 & 1.57 & 0.0067 & 47792 & 5.33 \\
\hline 800 & IPI00847635 & SERPINA3 & Isoform 1 of alpha-1-antichymotrypsin & 216 & 1.22 & 0.0273 & 47792 & 5.33 \\
\hline 814 & IPI00219330 & ILF3 & Isoform 5 of Interleukin enhancer binding factor 3 & 252 & -1.35 & 0.0205 & 74959 & 8.4 \\
\hline 869 & IPI00783625 & SERPINB5 & Isoform 1 of Serpin B5 & 120 & 1.27 & 0.0356 & 42530 & 5.72 \\
\hline $872^{*}$ & IPI00847635 & SERPINA3 & Isoform 1 of alpha-1-antichymotrypsin & 111 & 1.39 & 0.0456 & 47792 & 5.33 \\
\hline 876 & IPI00847635 & SERPINA3 & Isoform 1 of alpha-1-antichymotrypsin & 283 & 1.24 & 0.0424 & 47792 & 5.33 \\
\hline 976 & IPI00004657 & HLA-B & HLA class 1 histocompatibility antigen & 102 & 1.27 & 0.0150 & 40777 & 5.57 \\
\hline 980 & IPI00004657 & HLA-B & HLA class 1 histocompatibility antigen & 121 & 1.34 & 0.0383 & 40777 & 5.57 \\
\hline 981 & IPI00004657 & HLA-B & HLA class 1 histocompatibility antigen & 101 & 1.57 & 0.0008 & 40777 & 5.57 \\
\hline 1080 & IPI00166729 & AZGP1 & Zinc alpha 2 glycoprotein precursor & 147 & -1.34 & 0.0031 & 34258 & 5.71 \\
\hline 1177 & IPI00555812 & GC & Vitamin D binding protein precursor & 104 & -1.28 & 0.0151 & 52963 & 5.4 \\
\hline 1186 & IPI00641737 & $\mathrm{HP}$ & Haptoglobin & 92 & -1.29 & 0.0374 & 45205 & 6.13 \\
\hline 1374 & IPI00978715 & $\mathrm{CLU}$ & Clusterin & 109 & -1.25 & 0.0106 & 52495 & 5.88 \\
\hline 1381 & IPI00410313 & KIR3KL3 & Killer cell immunoglobulin like receptor 3DL3 & 132 & 1.25 & 0.0144 & 45470 & 7.27 \\
\hline 1392 & IPI00022391 & APCS & Serum Amyloid P component & 181 & 1.48 & 0.0223 & 25837 & 6.1 \\
\hline
\end{tabular}


Table 2 Proteins showing differential responses (Continued)

\begin{tabular}{lllllll}
\hline 1487 & IPI00386246 & AMPH & Amphiphysin I variant CT3, fragment & 119 & 1.24 & 4.23 \\
1796 & IPI00007879 & SRF & Serum response factor & 132 & 1.21 & 31195 \\
\hline
\end{tabular}

The 45 identified differential spots found among biological replicates of healed versus dehisced wounds (corresponding to $t$-test $<0.05$ and fold change cutoff $>$ 1.2) were identified via LC-MS/MS and yieled 25 unique protein identifications. The table includes spot number, IPI database number, gene name, protein name, MASCOT identification score, fold change and t-test of expression between healed and dehisced wounds, theoretical molecular weight and pl. *Indicates the 9 proteins selected as markers by discriminate analysis. Spot numbers 332, 336, 548, 763, 978, and 1797 were unable to be confidently identified.

can be used to differentiate and possibly predict wound outcome. Figure 2B shows hierarchical clustering of the differential proteins, using the average abundance of each spot within each experimental group. Figure $2 \mathrm{C}$ was produced by cluster analysis using the 52 differential spots; the spot maps showing similar protein expression patterns are clustered together. Similar to the PCA result, hierarchical clustering adequately separated healed spot maps from dehisced spot maps.

\section{K-means protein clusters and functions}

K-means partitioning analysis, within the DeCyder EDA module, exposes protein spot clusters exhibiting similar expression patterns (Figure 3). Interestingly, many of these proteins regulate different aspects of immunity and inflammatory responses. Specifically, cluster 1 is comprised of 5 (spot no. 337, 343, 344, 345, 347) of 12 separate spots with nearly identical molecular weights and slightly shifted pI values, encompassing the left half of the horizontal spot streak. All spots were identified as complement $\mathrm{C} 3$ protein and are individually, as well as collectively, upregulated in dehisced wound effluent samples. This acidic pI shift is commonly caused by post translational modifications (PTMs) [18], such as phosphorylation, which is a key regulatory mechanism in most systemic responses [19] that alters activation state of proteins [17]. In particular, phosphorylation has been shown to activate complement C3 by increasing complement binding [20] and opsonization [21] of invading pathogens, and is involved in anti-inflammatory regulatory mechanisms [22]. These data suggest that not only the overall protein expression level is important, but the abundance of certain isoforms that are a result of specific PTMs can help discriminate between healed and dehisced wound effluent.

The set of 25 unique differential proteins were functionally categorized using CateGOrizer according to the Immune System gene classes classification list (Figure 4). The largest functional class is metabolism, which is consistent with a large number of proteins having some involvement in cellular metabolism. The second largest category is stress response, which relates to the systemic impact of a major wound on the patient. These data strongly suggest that host proteins involved in responding to stress are changing abundance according to wound outcome. Moreover, these results are consistent with previous studies showing the importance of the stress response in wound healing [23-26].

\section{Discriminate analysis}

Patterns of differentially expressed proteins were analyzed via the EDA module to determine the appropriate biomarker panel that effectively discriminates between healed and dehisced wound effluent (Table 3). Panel A displays the 9 selected protein biomarkers with the respective discrimination accuracy $(83.83 \% \pm 2.8)$ and Panel B lists their gene names and protein identifications. These markers include protocadherin 17, serine/ threonine protein kinase 3, receptor type tyrosine protein phosphotase precursor, ceruloplasmin (2 spots), complement C3 (2 spots), xaa-pro aminopeptidase 1, and alpha-1-antichymotrypsin. Most importantly, these proteins could be used in a biomarker panel to determine which sample a particular host proteome belongs to and be further developed for use in a prognostic protein panel to aid physicians in selecting appropriate traumatic wound trauma treatment. Thus, 2-D DIGE data have revealed a set of protein biomarkers which can effectively discriminate between healed and dehisced wound effluent samples.

\section{Discussion}

Initial treatment of traumatic- and other combat-related injuries involves aggressive resuscitation measures in conjunction with debridement procedures that are geared towards achieving hemostasis and the removal of devitalized tissue. Wounds are treated with negative pressure wound therapy, and left open for subsequent serial debridement procedures. This is necessary because the zone of injury in traumatic- and other high-energy wounds may not be obvious at the outset, and evolves over time. As such, timing of definitive closure is largely subjective, as the surgeon weighs the benefits of successful wound closure, with the risk of wound failure which will necessitate further, perhaps more aggressive, debridement procedures, and can ultimately jeopardize fracture fixation and/or current levels of amputation. In addition, treatment of failed wounds prolongs the hospital length of stay and delays rehabilitation, resulting in an increase of healthcare costs to both the payer and patient. The main cause for this subjective decision is the lack of techniques that can objectively assess the 

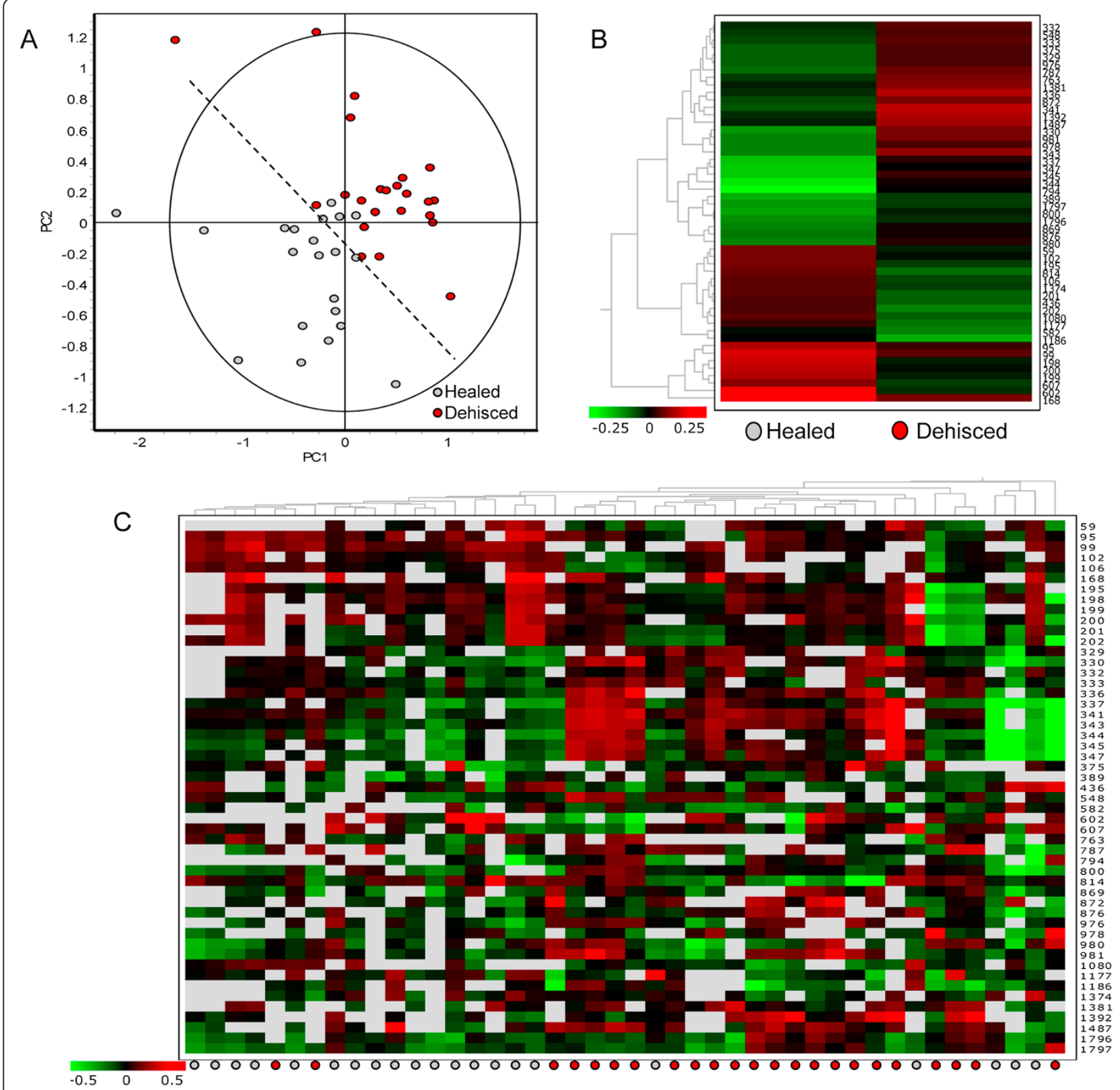

Figure 2 DeCyder cluster analysis. Fifty two verified differential expression protein spots (t-test $>0.5$, fold change $>1.2$ ) were used for the following analyses using DeCyder Extended Data Analysis. (A) Principle component analysis shows good separation between healed and dehisced samples; each dot represents an individual gel spot map. (B) Hierarchical clustering using the average abundance of differential spots for each experimental group, experimental groups are displayed in columns and protein spots by row, differential expression is displayed by color (red being up-regulated and green being down-regulated relative to the pooled standard. Clusters of differential proteins showing similar expression patterns are further defined in Figure 4. (C) Hierarchical clustering of 44 spot maps according to the 52 differential protein spots, individual patient spot maps are displayed by column and protein spots by rows.

suitability of a wound for closure and/or accurately portend successful wound healing [27].

Wound effluent (exudate) has proven to be a rich source of protein biomarkers that are associated with wound healing outcome in other types of extremity wounds. Two research groups have used a similar gel electrophoresis-based technique, one dimensional SDS-
PAGE followed by band excision and LC-MS/MS protein identification, to analyze the proteome of wound effluent. Eming et al. [28] analyzed patient effluent from healing and nonhealing venous leg ulcer wounds and identified 149 differentially expressed proteins. Many of these proteins are known to be involved in persistent inflammatory or tissue destruction responses which allow 


\begin{tabular}{|c|c|c|c|c|c|c|}
\hline $\begin{array}{l}\text { Kmeans Partition } \\
\text { Cluster Analysis }\end{array}$ & 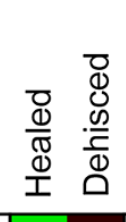 & $\begin{array}{l}\text { i } \\
\text { के } \\
\text { की }\end{array}$ & 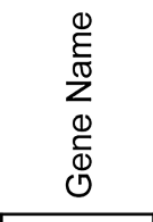 & & 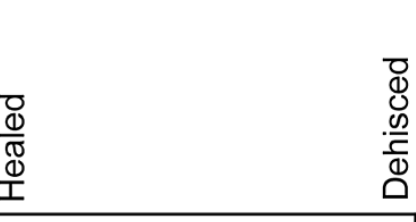 & Biological Processes \\
\hline $\begin{array}{c}\text { Cluster } 1 \\
\text { (q: } 95.2, \text { no: } 5 \text { ) }\end{array}$ & & $\begin{array}{l}337 \\
343 \\
344 \\
345 \\
347\end{array}$ & $\begin{array}{l}\mathrm{C} 3 \\
\mathrm{C} 3 \\
\mathrm{C} 3 \\
\mathrm{C} 3 \\
\mathrm{C} 3\end{array}$ & 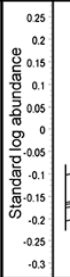 & & $\begin{array}{l}\text { Innate immunity, inflammatory } \\
\text { response }\end{array}$ \\
\hline $\begin{array}{c}\text { Cluster } 2 \\
\text { (q: } 91.0, \text { no: } 2 \text { ) }\end{array}$ & & $\begin{array}{l}602 \\
607\end{array}$ & $\begin{array}{l}\text { F7 } \\
\text { F7 }\end{array}$ & 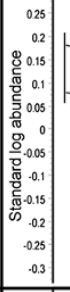 & & Blood coagulation, hemostasis \\
\hline $\begin{array}{c}\text { Cluster } 3 \\
\text { (q: } 78.5, \text { no: } 2 \text { ) }\end{array}$ & & $\begin{array}{l}1177 \\
1186\end{array}$ & $\begin{array}{l}\text { GC } \\
\text { HP }\end{array}$ & 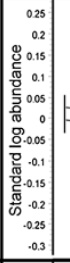 & & $\begin{array}{c}\text { Transport } \\
\text { Immunity, defense response }\end{array}$ \\
\hline $\begin{array}{c}\text { Cluster } 4 \\
\text { (q: } 56.3, \text { no: } 13 \text { ) }\end{array}$ & 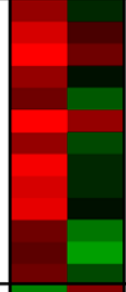 & $\begin{array}{l}59 \\
95 \\
99 \\
102 \\
106 \\
168 \\
195 \\
198 \\
199 \\
200 \\
201 \\
202 \\
1374 \\
\end{array}$ & \begin{tabular}{|l|} 
PER1 \\
PCDH17 \\
STKK36 \\
USP 32 \\
PARG \\
PTPRJ \\
CP \\
CP \\
CP \\
CP \\
CP \\
CLU \\
\end{tabular} & 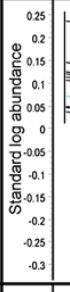 & Nw & $\begin{array}{c}\text { Biological rhythms, transcription } \\
\text { Cell adhesion } \\
\text { Cilium biogenisis/legradation } \\
\text { Ubl conjugation pathway } \\
\text { Detection of bacterium } \\
\text { Negative regulation of cell growth/prolif } \\
\text { Copper and ion transport } \\
\text { Innate immunity, apoptosis } \\
\end{array}$ \\
\hline $\begin{array}{c}\text { Cluster } 5 \\
\text { (q: } 46.1, \text { no: } 9 \text { ) }\end{array}$ & & \begin{tabular}{|l}
787 \\
869 \\
872 \\
876 \\
976 \\
980 \\
981 \\
1392 \\
1487 \\
\end{tabular} & \begin{tabular}{|l|} 
FGG \\
SERPINB5 \\
SERPINA3 \\
SERPINA3 \\
HLA-B \\
HLA-B \\
HLA-B \\
APCS \\
AMPH \\
\end{tabular} & 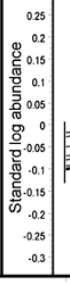 & 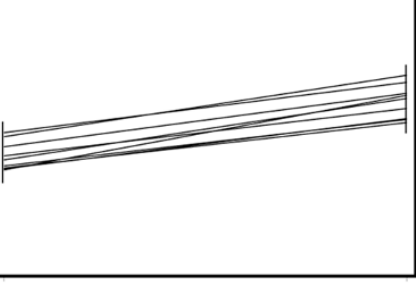 & \begin{tabular}{|c} 
Blood coagulation, hemostasis \\
Regulation of proteolysis \\
Acute phase inflammatory response \\
Regulation of immune response \\
Acute phase response \\
Endocytosis, synaptic transmission \\
\end{tabular} \\
\hline
\end{tabular}

for a better understanding of disease progression in this type of wound. Escalante et al. [29] analyzed the proteome of effluent collected from mice injected with 2 different types of snake venom enzymes. Their results showed a total of 78 differentially expressed proteins (10 serum proteins, 34 cytosolic proteins, 16 keratins, 2 macroglobulins, and 16 extracellular matrix proteins) which provided novel information on the tissue damaging pathogenic mechanisms of these toxins and the subsequently triggered inflammatory reaction. Taken together, these studies provide evidence that wound effluent directly reflects the wound site microenvironment and is, therefore, a suitable candidate for identifying protein biomarkers that can discriminate between various stages of healing.

Other studies have used gel-based proteomics to examine wound effluent from chronic wounds. For example, Upton and coworkers, applying the same affinity chromatography used in this manuscript, found that removal of high abundant proteins enhanced the ability to 

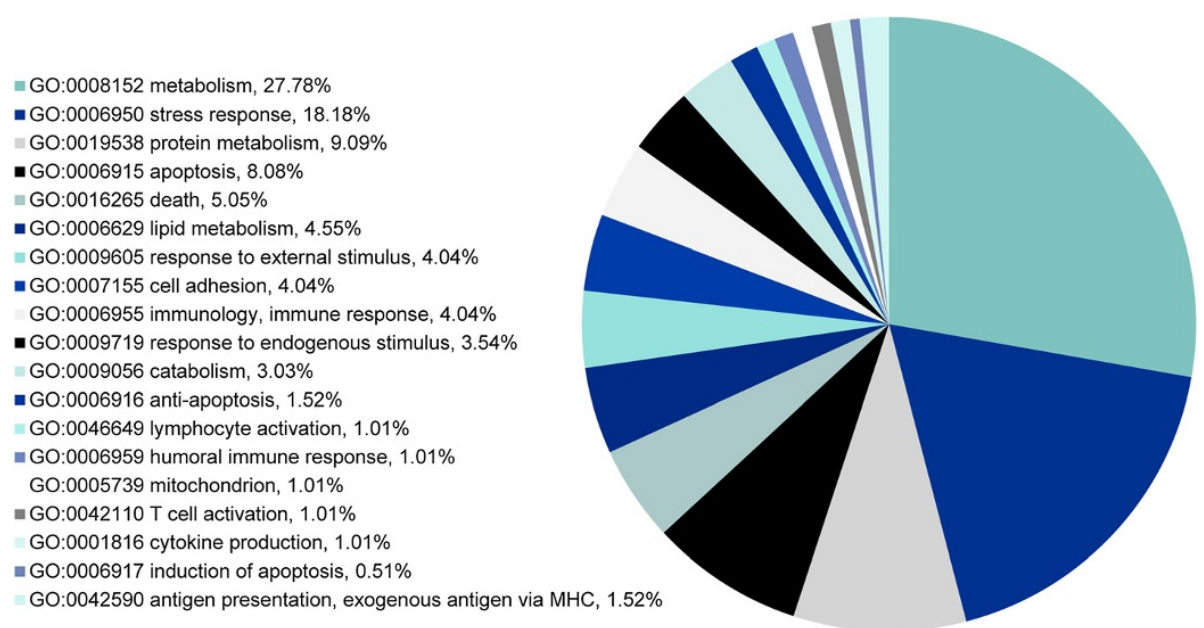

Figure 4 Functional classifications. The list of 45 identified differential proteins were functionally categorized into classes according to the Immune System Gene classification list using the CateGOrizer online tool.

detect lower abundant proteins in chronic wound fluid [30]. The same group produced a review article on the state of proteomics in chronic wound research and suggested affinity chromatography can also be beneficial to compensate for dynamic range problems normally associated with gel-based proteomics. A further suggestion to increase the dynamic range of $2 \mathrm{D}$ gels is to use improved $\mathrm{pI}$ separations. This review also suggested that using methods such as 2-D DIGE could compensate for the variable protein amounts and small clinical samples available for wound research [31]. Herein, we use these gel proteomic enhancements, namely, 2-D DIGE with large format gels that increase the pI separation and affinity chromatography to improve the dynamic range of the studied proteome. Other important literature showing proteomic characterization of chronic wound fluid comes from Wyffels and coworkers, who published two articles using different techniques (one using gels, the other using MS and protein arrays) [32,33]. Their earlier manuscript shows proteomic differences between the interior and periphery of wounds using 2DE. They also found differences between chronic and healed wounds, identifying S100A9 as a putative biomarker of wound healing. They report that $2 \mathrm{DE}$ is not optimal for the characterization of the protein profile of chronic wounds and alternate techniques, mass spectrometry and protein arrays, which they used in the more recent publication are needed. The use of multiple proteomic techniques for full characterization is optimal and taken together, the two papers from Wyfells and coworkers show a comprehensive approach to proteomic characterization with the use of the three main proteomic characterization techniques:

Table 3 Discriminate analysis

\begin{tabular}{lllll}
\hline A. Comparison (left vs. right) & Differential Proteins & Markers selected & Accuracy (\%) \\
\hline Healed & Dehisced & 52 & 9 & $83.83 \pm 2.8$
\end{tabular}

\section{B. Healed vs. Dehisced Discriminate Markers}

$\begin{array}{lll}\text { Spot No. } & \text { Gene Name } & \text { Protein Name } \\ 95 & \text { PCH17 } & \text { Protocadherin 17 } \\ 99 & \text { STK36 } & \text { Serine/threonine protein kinase 3 } \\ 168 & \text { PTPRJ } & \text { Receptor type tyrosine protein phosphotase precursor } \\ 195 & \text { CP } & \text { Ceruloplasmin } \\ 198 & \text { CP } & \text { Ceruloplasmin } \\ 341 & \text { C3 } & \text { Complement C3 } \\ 343 & \text { C3 } & \text { Complement C3 } \\ 375 & \text { XPNPEP1 } & \text { Xaa-Pro aminopeptidase 1 } \\ 872 & \text { SERPINA3 } & \text { Alpha-1-antichymotrypsin }\end{array}$

Differential proteins were used to determine the appropriate marker selection panel of proteins that effectively discriminate between healed and dehisced effluent samples. A total of 9 markers were selected which give greater than $83 \%$ accuracy (panel A), the corresponding protein identifications are shown in panel B. 
gels, MS, and arrays. We support the use of these additional techniques for comprehensive proteomic characterization, however, an important distinction exists between the gel-based work in the 2010 Wyfells manuscript and ours. We use 2-D DIGE as compared to conventional 2DE. The 2-D DIGE approach uses an internal pooled standard that removes the major problem with gelbased proteomics, namely the gel to gel variation. In addition, the use of the 2-D DIGE system allows for lower level detection and increases the potential pool of putative biomarkers. Nonetheless, this literature from chronic wound fluid proteomics helps guide our future work, which will include additional proteomic techniques for more comprehensive characterization.

Current biomarker research from our group, involving traumatic and other high-energy combat wounds, is based on the analysis of serum, effluent and tissue biopsy specimens [11-13]. This work led to a unique understanding of the mechanisms involved in healing with regards to the timing of surgical wound closure. Many proinflammatory proteins and cytokines show increased expression in dehiscing wounds: procalcitonin [12] and IL-6 [11] (serum and effluent); IL-8 [11] (serum and tissue biopsy); MMP-2, MMP-3, MMP-7 [13], CCL3 [11] (serum only); IL-1 alpha/beta, CCL2, and GM-CSF [11] (tissue biopsy only). Similarly, other inflammatory mediator proteins display decreased expression in wounds that failed to heal: IL-13 (effluent [12] and tissue biopsy [11]); CCL5 [12], IL-2, inducible protein-10 [11] (effluent only); IL-4, IL-5 [11] (tissue biopsy only). The biomarkers found in this current study will be used along with these other ongoing cytokine-based immunoassay results to further the development of assays that can characterize wounds and lead to improved prognostic tools. We aim to use these prognostic tools to aid physicians in predicting wound outcome and provide optimal care for traumatic- and other combat-related injuries.

In this study, the classes of proteins that make up the highest percent of change include those involved with metabolism, stress, and cell death (Figure 4). These results are not surprising as wound healing requires substantial changes in cell growth, cell maintenance, and cell death to be completed successfully. Over $40 \%$ of the proteins that are differentially expressed involve metabolism, while almost $20 \%$ are involved in stress, and another $13+\%$ involve apoptosis. The emphasis of differential expression on these protein classes suggests that specific pathways that lead to cell growth, autophagy, and cell death are vital for appropriate wound healing. Moreover, the pattern of protein expression, especially given sufficient redundancy for certain cell functions, may also help to characterize appropriate wound healing. Future characterization of protein expression changes with additional diverse datasets may lead to functional models that can characterize new wounds and help determine their treatment route leading to appropriate healing.

Dysfunction and dysregulation of inflammatory and immune responses as a contributing factor to determining wound outcome support the result of this wound effluent proteomic profiling study of combat wound effluent. Of the 52 differential proteins, complement C3 (C3), alpha-1-antichymotrypsin (SERPINA3), immunoglobulin superfamily member 21 (IGSF21), HLA class 1 histocompatability antigen (HLA-B), clusterin (CLU), haptoglobin (HP), serum amyloid P component (APCS) have roles in immune and/or inflammatory responses and were found to be differentially expressed between healed and dehisced wound effluent samples. In addition, two proteins involved in hemostasis showed differential expression, i.e. decrease of coagulation factor VII (F7) and increase of fibrinogen gamma chain (FGG) in dehisced samples.

Most importantly, the discriminate marker panel (Table 3) displays the 9 protein spots that can differentiate an effluent sample as healed or dehisced with an accuracy of greater than $83 \%$. Accordingly, these proteins have the potential to be developed into a prognostic panel which can be used by physicians to determine a wound's likeliness to heal normally or dehisce after surgical closure. Evaluating wound effluent from traumaticand other combat wounds using the advanced proteomic method of 2-D DIGE is an important step to understanding the protein expression changes in the local wound environment.

\section{Conclusions}

This research contributes to our development of a personalized clinical treatment of combat wounds which will help mitigate the risk of wound closure in this challenging clinical scenario, and potentially lead to improved healing outcomes while decreasing the number of surgical procedures, hospital length of stay and costs.

\section{Abbreviations}

DIGE: Differential gel electrophoresis; LC-MS/MS: Liquid chromatography mass spectrometry mass spectrometry; NPWT: Negative-pressure wound therapy; BVA: Biological variation analysis; EDA: Extended data analysis; PCA: Principle component analysis.

\section{Competing interests}

The authors declare that they have no competing interests of either financial or non-financial nature regarding the work described in the present manuscript and its publication.

\section{Authors' contributions}

$B A C, A E$, and PAL initially conceived of and designed the proteomics experiments. The overall design of the study, including planning and various aspects of interpretation of results, involved BAC, AE, JAF, TSB, BCK, CJ, NAB, EE and PAL. AE and BAC acquired the data. TSB, JAF and EE supplied crucial samples and clinical information. $A E P A L$ and $B A C$ generated the initial draft of the manuscript. BAC, AE, JAF, TSB, BCK, CJ, NAB, EE, and PAL provided critical revisions. All authors read and approved the final manuscript. 


\section{Acknowledgements}

The project depicted was sponsored by the U.S. Army Medical Research and Materiel Command (Award number: MIPR1EO89M1115). The U.S. Army Medical Research Acquisition Activity (820 Chandler Street, Fort Detrick MD 21702-5014) is the awarding and administering acquisition office. Partial funding for this project was also provided by the Proteomics Initiative of the Department of Pathology and Laboratory Medicine at U.C. Davis. We gratefully acknowledge Ray Lenhoff for very helpful discussions in the earliest stage of this study. The opinions or assertions contained herein are the private views of the authors, and are not to be construed as official, or as reflecting the position or policy of the government, including the Departments of the Army, Navy, or Defense.

\section{Disclaimer}

The views expressed in this manuscript are those of the authors and do not reflect the official policy of the Department of the Army, Department of the Navy, the Department of Defense or the United States Government. This effort was supported (in part) by the U.S. Navy Bureau of Medicine and Surgery under the Medical Development Program and Office of Naval Research.

Some authors are military service members (or employees of the U.S. Government). This work was prepared as part of our official duties. Title $17 \mathrm{U}$. S.C. 105 provides the "Copyright protection under this title is not available for any work of the United States Government." Title 17 U.S.C. 101 defines a U.S. Government work as a work prepared by a military service member or employee of the U.S. Government as part of that person's official duties. I We certify that all individuals who qualify as authors have been listed; each has participated in the conception and design of this work, the analysis of data (when applicable), the writing of the document, and the approval of the submission of this version; that the document represents valid work; that if we used information derived from another source, we obtained all necessary approvals to use it and made appropriate acknowledgements in the document; and that each takes public responsibility for it.

\section{Author details}

'Department of Pathology and Laboratory Medicine, School of Medicine, University of California at Davis, Davis, CA, USA. ${ }^{2}$ Center for Comparative Medicine, University of California at Davis, Davis, CA, USA. ${ }^{3}$ Department of Orthopaedics, National Military Medical Center, Bethesda, MD, USA. ${ }^{4}$ Regenerative Medicine Department, Naval Medical Research Center, Silver Spring, MD, USA. ${ }^{5}$ Department of Wound Infections, Walter Reed Army Institute of Research, Silver Spring, MD, USA. ${ }^{6}$ Department of Medicine, F Edward Hebert School of Medicine, Uniformed Services University of the Health Sciences, Bethesda, MD, USA. ${ }^{7}$ Physical \& Life Sciences Directorate, Lawrence Livermore National Laboratory, Livermore, CA, USA. ${ }^{8}$ Norman M. Rich Department of Surgery, Uniformed Services University of the Health Sciences, Bethesda, MD, USA.

\section{Received: 13 July 2013 Accepted: 30 October 2013}

Published: 6 November 2013

\section{References}

1. Ritenour AE, Blackbourne LH, Kelly JF, McLaughlin DF, Pearse LA, Holcomb $J B$, et al: Incidence of primary blast injury in US military overseas contingency operations: a retrospective study. Annals of surgery 2010, 251:1140-4.

2. Ramasamy A, Harrisson SE, Clasper JC, Stewart MP: Injuries from roadside improvised explosive devices. J Trauma 2008, 65:910-4.

3. McKay BJ, Bir CA: Lower extremity injury criteria for evaluating military vehicle occupant injury in underbelly blast events. Stapp Car Crash J 2009, 53:229-49.

4. Langworthy MJ, Smith JM, Gould M: Treatment of the mangled lower extremity after a terrorist blast injury. Clin Orthop Relat Res 2004, 422:88-96.

5. Brown TS, Hawksworth JS, Sheppard FR, Tadaki DK, Elster E: Inflammatory response is associated with critical colonization in combat wounds. Surg Infect (Larchmt) 2011, 12:351-7.

6. Davis TA, O'Brien FP, Anam K, Grijalva S, Potter BK, Elster EA: Heterotopic ossification in complex orthopaedic combat wounds: quantification and characterization of osteogenic precursor cell activity in traumatized muscle. J Bone Joint Surg Am 2011, 93:1122-31.
7. Covey DC: Blast and fragment injuries of the musculoskeletal system. $J$ Bone Joint Surg Am 2002, 84-A:1221-34.

8. Menke NB, Ward KR, Witten TM, Bonchev DG, Diegelmann RF: Impaired wound healing. Clin Dermatol 2007, 25:19-25.

9. Gosain A, DiPietro LA: Aging and wound healing. World I Surg 2004, 28:321-6.

10. Edwards R, Harding KG: Bacteria and wound healing. Curr Opin Infect Dis 2004, 17:91-6.

11. Hawksworth JS, Stojadinovic A, Gage FA, Tadaki DK, Perdue PW, Forsberg J, et al: Inflammatory biomarkers in combat wound healing. Annals of surgery. 2009, 250:1002-7.

12. Forsberg JA, Elster EA, Andersen RC, Nylen E, Brown TS, Rose MW, et al: Correlation of procalcitonin and cytokine expression with dehiscence of wartime extremity wounds. J Bone Joint Surg Am 2008, 90:580-8.

13. Utz ER, Elster EA, Tadaki DK, Gage F, Perdue PW, Forsberg JA, et al: Metalloproteinase expression is associated with traumatic wound failure. J Surg Res 2010, 159:633-9.

14. Raimondo F, Salemi C, Chinello C, Fumagalli D, Morosi L, Rocco F, et al: Proteomic analysis in clear cell renal cell carcinoma: identification of differentially expressed protein by 2-D DIGE. Mol Biosyst 2012, 8:1040-51.

15. Corzett TH, Fodor IK, Choi MW, Walsworth VL, Turteltaub KW, McCutchenMaloney SL, et al: Statistical analysis of variation in the human plasma proteome. J Biomed Biotechnol 2010, 2010:258494.

16. Chromy BA, Luciw PA, Brown TS EE: Proteomic Sample preparation for blast wound characterization. ; 2013. In Press.

17. Seo J, Lee KJ: Post-translational modifications and their biological functions: proteomic analysis and systematic approaches. J Biochem Mo/ Biol 2004, 37:35-44.

18. Zhu K, Zhao J, Lubman DM, Miller FR, Barder TJ: Protein pl shifts due to posttranslational modifications in the separation and characterization of proteins. Anal Chem 2005, 77:2745-55.

19. Hunter T: Protein kinases and phosphatases: the yin and yang of protein phosphorylation and signaling. Cell 1995, 80:225-36.

20. Nilsson-Ekdahl K, Nilsson B: Phosphorylation of C3 by a casein kinase released from activated human platelets increases opsonization of immune complexes and binding to complement receptor type 1. Eur J Immunol 2001, 31:1047-54.

21. Ekdahl KN, Nilsson B: Alterations in C3 activation and binding caused by phosphorylation by a casein kinase released from activated human platelets. J Immunol 1999, 162:7426-33.

22. Kawakami F, Shimoyama Y, Ohtsuki K: Characterization of complement C3 as a glycyrrhizin (GL)-binding protein and the phosphorylation of C3alpha by $\mathrm{CK}-2$, which is potently inhibited by GL and glycyrrhetinic acid in vitro. J Biochem 2003, 133:231-7.

23. Jiang F, Zhang Y, Dusting GJ: NADPH oxidase-mediated redox signaling: roles in cellular stress response, stress tolerance, and tissue repair. Pharmacol Rev 2011, 63:218-42.

24. Doshi BM, Perdrizet GA, Hightower LE: Wound healing from a cellular stress response perspective. Cell Stress Chaperones 2008, 13:393-9.

25. Coelho V, Broere F, Binder RJ, Shoenfeld Y, Moudgil KD: Heat-shock proteins: inflammatory versus regulatory attributes. Cell Stress Chaperones 2008, 13:119-25.

26. Mustoe TA, O'Shaughnessy K, Kloeters O: Chronic wound pathogenesis and current treatment strategies: a unifying hypothesis. Plast Reconstr Surg 2006, 117:35S-41S.

27. Hahm G, Glaser JJ, Elster EA: Biomarkers to predict wound healing: the future of complex war wound management. Plast Reconstr Surg 2011, 127(Suppl 1):21S-6S.

28. Eming SA, Koch M, Krieger A, Brachvogel B, Kreft S, Bruckner-Tuderman L, et al: Differential proteomic analysis distinguishes tissue repair biomarker signatures in wound exudates obtained from normal healing and chronic wounds. J Proteome Res 2010, 9:4758-66.

29. Escalante T, Rucavado A, Pinto AF, Terra RM, Gutierrez JM, Fox JW: Wound exudate as a proteomic window to reveal different mechanisms of tissue damage by snake venom toxins. J Proteome Res 2009, 8:5120-31.

30. Fernandez ML, Broadbent JA, Shooter GK, Malda J, Upton Z: Development of an enhanced proteomic method to detect prognostic and diagnostic markers of healing in chronic wound fluid. Br J Dermatol 2008, 158:281-90. 
31. Broadbent J, Walsh T, Upton Z: Proteomics in chronic wound research: potentials in healing and health. Proteomics Clin Appl 2010, 4:204-14.

32. Wyffels JT, Fries KM, Randall JS, Ha DS, Lodwig CA, Brogan MS, et al: Analysis of pressure ulcer wound fluid using two-dimensional electrophoresis. Int Wound J 2010, 7:236-48.

33. Edsberg LE, Wyffels JT, Brogan MS, Fries KM: Analysis of the proteomic profile of chronic pressure ulcers. Wound Repair Regen 2012, 20:378-401.

doi:10.1186/1479-5876-11-281

Cite this article as: Chromy et al:: Wound outcome in combat injuries is associated with a unique set of protein biomarkers. Journal of

Translational Medicine 2013 11:281.

\section{Submit your next manuscript to BioMed Central and take full advantage of:}

- Convenient online submission

- Thorough peer review

- No space constraints or color figure charges

- Immediate publication on acceptance

- Inclusion in PubMed, CAS, Scopus and Google Scholar

- Research which is freely available for redistribution 